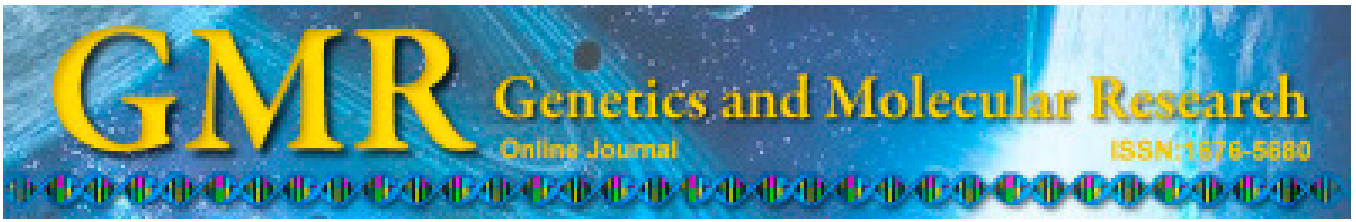

\title{
Varicocele and male infertility in Northeast China: Y chromosome microdeletion as an underlying cause
}

\author{
R.L. Dai ${ }^{1}$,Y. Hou ${ }^{2}$, F.B. Li ${ }^{3}$, J.M. Yue ${ }^{1}$, Q. Xi ${ }^{1}$ and R.Z. Liu ${ }^{1}$ \\ ${ }^{1}$ Center for Reproductive Medicine, First Hospital, Jilin University, \\ Changchun, China \\ ${ }^{2}$ Center for Urology, Third Hospital, Jilin University, Changchun, China \\ ${ }^{3}$ Center for Andrology, First Hospital, Jilin University, Changchun, China \\ Corresponding author: R.Z. Liu \\ E-mail: lanxin910@163.com
}

Genet. Mol. Res. 14 (2): 6583-6590 (2015)

Received December 4, 2014

Accepted April 6, 2015

Published June 12, 2015

DOI http://dx.doi.org/10.4238/2015.June.12.13

\begin{abstract}
The prevalence of Y chromosome microdeletions among azoospermic, severe oligozoospermic, moderate oligozoospermic, and mild oligozoospermic patients with varicocele-related and idiopathic infertility shows conflicting data in Asian countries. We aimed to detect this frequency in Northeast China, and investigated spermatogenic defects whether associated with varicocele or $\mathrm{Y}$ chromosome microdeletions. All samples underwent a thorough physical examination, semen analysis, and PCR analyses for Y chromosome microdeletions. We randomly selected 150 infertile non-obstructive azoospermic patients with left varicocele (Group 1), 150 idiopathic non-obstructive azoospermic infertility patients (Group 2), 150 infertile severe oligozoospermic patients with left varicocele (Group 3), 150 idiopathic severe oligozoospermic infertility patients (Group 4), 150 infertile moderate oligozoospermic patients with left varicocele (Group 5), 150 idiopathic moderate oligozoospermic infertility patients (Group 6), 150 infertile mild oligozoospermic patients with left varicocele (Group 7),
\end{abstract}


150 idiopathic mild oligozoospermic infertility patients (Group 8), and 60 healthy unrelated men with proven fertility were recruited as control subjects (Group 9). We observed that our samples from Northeastern China had a higher frequency of microdeletions among the nonobstructive azoospermic individuals with varicocele, as compared with other Asian countries. Furthermore, the spermatogenic defect is due to the underlying Y chromosome microdeletion, and not the varicocele itself. Although varicocele is not the cause of male infertility, it may be associated with male infertility in the Northeastern Chinese population.

Key words: Varicocele; Male infertility; $\mathrm{Y}$ chromosome microdeletion; Azoospermia; Severe oligozoospermia

\section{INTRODUCTION}

Varicocele is an abnormal dilation of the pampiniform plexus of testicular veins, whereby the veins are swollen and twisted over the testicle, ranging from azoospermia to oligozoospermia (Moro et al., 2000). It occurs on the left side in 78-93\% of cases (Redmon et al., 2002), and effects approximately $40 \%$ of the reproductive-aged population (Marmar, 2001).

The Y chromosome contains a few genes that control spermatogenesis, and most of the microdeletions related to azoospermia or oligozoospermia occur in the long (q) arm of the Y-chromosome. Within the Yq region, the azoospermia factor (AZF) region is divided into 3 subregions (AZFa-c) that are approximately $800 \mathrm{~kb}, 3.2 \mathrm{Mb}$, and $3.5 \mathrm{Mb}$ in size, respectively (Briton-Jones and Haines, 2000; Gatta et al., 2002). The genes in the AZF region are considered critical for spermatogenesis, and the frequency of $Y$ chromosome microdeletions has been associated with the severity of spermatogenic defects (Krausz et al., 2001). Y chromosome microdeletions are considered to be one of the most important genetic causes leading to male infertility.

To date, varicocele is often considered as the common cause of male infertility in some studies. Indeed, for centuries, the literatures have indicated an association between varicocele and male infertility. For instance, some reports recognized that semen quality could be improved after varicocele repair. This was observed by Tulloch (1952), who described a patient with bilateral varicocele and azoospermia, whose sperm count increased to $27 \times 10^{6}$ after surgical corrections and he conceived a child. Also, Redmon et al. (2002) have shown the hypothesis that varicocele may not have any association with or effect on male fertility or it may be associated with, but is not the cause of, male subfertility. However, the primary cause of infertility is still unclear. Genetic abnormalities are thought to contribute to the cause of many unexplained cases of male infertility. Y chromosome microdeletions are particularly intriguing, and conflicting results have been reported with respect to the prevalence of Y chromosome microdeletions in varicocele patients.

The aim of the present study was to detect the prevalence of $\mathrm{Y}$ chromosome microdeletions in azoospermic, severe oligozoospermic, moderate oligozoospermic, and mild oligozoospermic patients among men with varicocele-related and idiopathic infertility in a Northeast Chinese population. By comparing these results with previously published reports, we investigated whether the spermatogenic defect was associated with varicocele or Y chromosome microdeletions. 


\section{MATERIAL AND METHODS}

\section{Patients}

We evaluated 3600 infertile male patients aged 20-47 years who attended the outpatient infertility clinic of the Andrology and Urology Departments of the First Hospital of Changchun, Jilin Province, Northeastern China, between November 6, 2006 and October 22, 2014. All patients underwent a thorough physical examination, semen analysis, and PCR analyses for Y chromosome microdeletions. We randomly selected 150 infertile non-obstructive azoospermic patients with left varicocele (Group 1), 150 idiopathic non-obstructive azoospermic infertility patients (Group 2), 150 infertile severe oligozoospermic patients with left varicocele (at least three semen samples with sperm counts of $<5$ million/mL, Group 3), 150 idiopathic severe oligozoospermic infertility patients (Group 4), 150 infertile moderate oligozoospermic patients with left varicocele (at least three semen samples with sperm counts of 5-10 million $/ \mathrm{mL}$, Group 5), 150 idiopathic moderate oligozoospermic infertility patients (Group 6), 150 infertile mild oligozoospermic patients with left varicocele (at least three semen samples with sperm counts of 10-20 million/mL, Group 7), 150 idiopathic mild oligozoospermic infertility patients (Group 8), and 60 healthy unrelated men with proven fertility (attending the Physical Examination Center, First Hospital for routine examination) were recruited as control subjects (Group 9).

The Ethics Committee of First Hospital approved this study, and all patients provided informed consent to participate in the study.

\section{Sample collection and routine semen analysis}

Semen analysis was performed for all patients according to the recommendations of the World Health Organization (1999). Semen samples were collected after 3-5 days of sexual abstinence, and they were left to liquefy for $30 \mathrm{~min}$ at $37^{\circ} \mathrm{C}$. Semen analysis included assessment of sperm concentration and motility. Throughout the study, the same technician performed all semen analyses. Concentration and motility were evaluated using computerassisted sperm analysis (CASA; WLJY-9000, China). Sperm motility was assessed by categorization into four grades of motility at $37^{\circ} \mathrm{C}$ : Grade A - rapid progressive sperm; Grade B - slow progressive sperm; Grade C - non-progressive sperm; and Grade D - immotile sperm. Sperm viability was evaluated by Eosin Y staining.

\section{DNA and PCR analyses}

Genomic DNA was isolated from peripheral blood lymphocytes using the Tiangen Blood DNA Extraction Mini Kit (Beijing Tiangen Biotech Co. Ltd., China). DNA samples obtained from normal men with proven fertility and normal women were used as positive and negative controls. And water was used as a blank control.

Based on the recommendations of the European Academy of Andrology and the European Molecular Genetics Quality Network, the patients were tested for the markers proposed by Simoni et al. (2004): sY84, sY86, sY127, sY134, sY143, sY152, sY254, sY255 and sY157, with sY14 (sex-determining region of the $\mathrm{Y}$ chromosome) and sex-chromosomal zinc-finger genes (ZFX/ZFY) as internal controls. PCR was carried out in a total volume of $20 \mu \mathrm{L}$. A PCR 
thermal cycler (Veriti 96-well PCR; Applied Biosystems, Carlsbad, CA, USA) was used to complete the PCR amplification. Each experiment was performed at least twice. Results were considered positive when a clear amplification product of the expected size was obtained. In cases of negative results, PCR was repeated two more times or until acceptable results were achieved.

\section{Statistical analysis}

The SPSS software (ver. 11.5; SPSS, Inc., Chicago, IL, USA) was used to perform statistical calculations. Differences were considered to be statistically significant when $\mathrm{P}<0.01$.

\section{RESULTS}

PCR for Y chromosome microdeletions were performed on all patients and controls. Microdeletions were found in $18.00 \%$ (27/150) of the non-obstructive azoospermic patients with left varicocele and in $6.00 \%(9 / 150)$ of the idiopathic non-obstructive azoospermic infertility patients. Furthermore, Y chromosome microdeletions were found in 11 severe oligozoospermic patients with left varicocele (7.33\%), 5 idiopathic severe oligozoospermic infertility patients (3.33\%), 4 moderate oligozoospermic patients with left varicocele $(2.67 \%)$, and 2 idiopathic moderate oligozoospermic infertility patients (1.33\%). There were no Y chromosome microdeletions in mild oligozoospermic and control groups (Table 1).

\begin{tabular}{|c|c|c|c|c|c|c|c|c|}
\hline \multirow[t]{2}{*}{ Group } & \multirow[t]{2}{*}{ Type of infertility } & \multirow[t]{2}{*}{$\mathrm{N}$} & \multirow[t]{2}{*}{ Seminal pattern } & \multirow{2}{*}{$\begin{array}{c}\text { No. of } \\
\text { microdeletions }\end{array}$} & \multicolumn{4}{|c|}{ No. of microdeletion in AZF region } \\
\hline & & & & & $\mathrm{AZFa}$ & $\mathrm{AZFb}$ & $\mathrm{AZFc}$ & $\mathrm{AZFb}+\mathrm{c}$ \\
\hline 1 & Left varicocele & 150 & Azoospermia & 27 & 2 & 2 & 14 & 9 \\
\hline 2 & Idiopathic infertility & 150 & Azoospermia & 9 & 1 & 1 & 5 & 2 \\
\hline 3 & Left varicocele & 150 & Severely oligozoospermia & 11 & 0 & 0 & 11 & 0 \\
\hline 4 & Idiopathic infertility & 150 & Severely oligozoospermia & 5 & 0 & 0 & 5 & 0 \\
\hline 5 & Left varicocele & 150 & Moderate oligozoospermia & 4 & 0 & 0 & 4 & 0 \\
\hline 6 & Idiopathic infertility & 150 & Moderate oligozoospermia & 2 & 0 & 0 & 2 & 0 \\
\hline 7 & Left varicocele & 150 & Mild oligozoospermia & 0 & 0 & 0 & 0 & 0 \\
\hline 8 & Idiopathic infertility & 150 & Mild oligozoospermia & 0 & 0 & 0 & 0 & 0 \\
\hline 9 & Fertility control & 60 & Normal & 0 & 0 & 0 & 0 & 0 \\
\hline
\end{tabular}

Among the 27 with microdeletions in Group 1,2 patients had microdeletions in the AZFa region, 2 had microdeletions in the AZFb region, 14 had microdeletions in the AZFc region, and 9 had microdeletions in the $\mathrm{AZFb}+\mathrm{c}$ regions. Among the 9 with microdeletions in Group 2, 1 patient had microdeletions in the AZFa region, 1 had microdeletions in the AZFb region, 5 had microdeletions in the AZFc region, and 2 had microdeletions in the $\mathrm{AZFb}+\mathrm{c}$ regions. All of the severely oligozoospermic and moderate oligozoospermic patients (including Groups 3, 4, 5, and 6) had microdeletions in the AZFc regions (Table 1).

A comparison of $\mathrm{Y}$ chromosome microdeletion frequencies in non-obstructive azoospermic patients with varicocele between this study and previous Asian studies that used the same inclusion criteria is shown in Table 2 . In our study, 27 non-obstructive azoospermic patients $(18.00 \%, 27 / 150)$ had Y-chromosome microdeletions, which is different from the results presented by other Asian studies, including those involving India, Turkey, and Eastern China (Jiangsu Province). Particularly disparate was the study by Sagnak et al. (2010) who thought 
that none of the patients in Turkey carried Y chromosome microdeletions. However, our results were consistent with those obtained in the study of Eastern China (Shandong Province).

\begin{tabular}{|c|c|c|c|c|c|c|}
\hline Authors & Country & $\begin{array}{c}\text { No. of } \\
\text { loci tested }\end{array}$ & $\begin{array}{l}\text { No. of varicocele } \\
\text { patients }\end{array}$ & $\begin{array}{l}\text { No. of varicocele } \\
\text { patients with } \\
\text { microdeletions }\end{array}$ & $\begin{array}{c}\text { Frequency of } \\
\text { microdeletion } \\
(\%)\end{array}$ & Deleted subregions \\
\hline Rao et al. (2004) & India & 18 & 57 & 1 & $1.75^{* *}$ & $\mathrm{AZFc}$ \\
\hline Dada et al. (2007) & India & 6 & 72 & 4 & $5.56^{*}$ & $\mathrm{AZFa} ; \mathrm{AZFa}+\mathrm{b} ; \mathrm{AZFb}+\mathrm{c}$ \\
\hline Sagnak et al. (2010) & Turkey & 19 & 51 & 0 & $0 * *$ & NR \\
\hline Gao et al. (2012) & $\begin{array}{l}\text { Eastern China } \\
\text { (Shandong Province) }\end{array}$ & 6 & 47 & 11 & 23.40 & $\begin{array}{l}\mathrm{AZFc} ; \mathrm{AZFa} ; \mathrm{AZFb} \\
\mathrm{AZFb}+\mathrm{c}\end{array}$ \\
\hline Song et al. (2005) & $\begin{array}{l}\text { Eastern China } \\
\text { (Jiangsu Province) }\end{array}$ & 6 & 81 & 3 & $3.70^{* *}$ & $\mathrm{AZFa} ; \mathrm{AZFc}$ \\
\hline This study & Northeast China & 9 & 150 & 27 & 18.00 & $\begin{array}{l}\mathrm{AZFa} ; \mathrm{AZFb} ; \mathrm{AZFb}+\mathrm{c} ; \\
\mathrm{AZFc}\end{array}$ \\
\hline
\end{tabular}

$* \mathrm{P}<0.05$, compared with our study. ${ }^{* *} \mathrm{P}<0.01$, compared with our study. $\mathrm{NR}=$ not reported.

A comparison of Y chromosome microdeletion frequencies in severely oligozoospermic patients with varicocele between this study and previous Asian studies is shown in Table 3. In our study, 11 severely oligozoospermic patients $(7.33 \%, 11 / 150)$ had Y chromosome microdeletions. Previous studies are consistent with the results of the present study, with the exception of those observed in the Eastern China (Shandong Province) study.

Patients of Group 1-8 all had some degree of testicular damage (Table 4).

Table 3. Comparison of the Y chromosome microdeletion frequency in severely oligozoospermic patients with varicocele in this study and other Asian studies.

\begin{tabular}{llccccc}
\hline Authors & Country & $\begin{array}{c}\text { No. of } \\
\text { loci tested }\end{array}$ & $\begin{array}{c}\text { No. of varicocele } \\
\text { patients }\end{array}$ & $\begin{array}{c}\text { No. of varicocele patients } \\
\text { with microdeletions }\end{array}$ & $\begin{array}{c}\text { Frequency of } \\
\text { microdeletion (\%) }\end{array}$ & $\begin{array}{c}\text { Deleted } \\
\text { subregions }\end{array}$ \\
\hline Rao et al. (2004) & India & 18 & 57 & 1 & 1.75 & AZFc \\
Dada et al. (2007) & India & 6 & 72 & 3 & 4.17 & AZFc \\
Sagnak et al. (2010) & Turkey & 19 & 51 & 1 & 1.96 & AZFc \\
Gao et al. (2012) & $\begin{array}{l}\text { Eastern China } \\
\text { (Shandong Province) }\end{array}$ & 6 & 57 & 11 & $19.30^{*}$ & AZFc \\
Song et al. (2005) & $\begin{array}{l}\text { Eastern China } \\
\text { (Jiangsu Province) }\end{array}$ & 6 & 81 & 11 & 1.23 & AZFc \\
This study & Northeast China & 9 & 150 & 11 & & 7.33 \\
\hline
\end{tabular}

$* \mathrm{P}<0.05$, compared with our study.

Table 4. Number of patients with testicular damage in different groups.

\begin{tabular}{|c|c|c|c|c|c|}
\hline \multirow[t]{2}{*}{ Group } & \multirow[t]{2}{*}{$\mathrm{N}$} & \multirow[t]{2}{*}{ Seminal pattern } & \multicolumn{3}{|c|}{ No. of patients } \\
\hline & & & Bilateral testis small & Left testis small & Normal \\
\hline 1 & 150 & Azoospermia & 89 & 26 & 35 \\
\hline 2 & 150 & Azoospermia & 74 & 8 & 68 \\
\hline 3 & 150 & Severely oligozoospermia & 71 & 8 & 71 \\
\hline 4 & 150 & Severely oligozoospermia & 41 & 18 & 91 \\
\hline 5 & 150 & Moderate oligozoospermia & 11 & 16 & 123 \\
\hline 6 & 150 & Moderate oligozoospermia & 7 & 13 & 130 \\
\hline 7 & 150 & Mild oligozoospermia & 5 & 6 & 139 \\
\hline 8 & 150 & Mild oligozoospermia & 3 & 2 & 145 \\
\hline 9 & 60 & Normal & 0 & 0 & 60 \\
\hline
\end{tabular}

Genetics and Molecular Research 14 (2): 6583-6590 (2015) 


\section{DISCUSSION}

Although it has long been recognized that varicoceles are closely related to male infertility, few studies have specifically examined whether varicoceles are associated with any genetic factors leading to spermatogenic defects in non-obstructive azoospermic, severe oligozoospermic, moderate oligozoospermic, and mild oligozoospermic infertile men with varicocele-related and idiopathic infertility. Y chromosome microdeletions are considered to one of the most important genetic causes related to male infertility. The selection of an appropriate sequence tagged site (STS) loci is critical in the determination of Y chromosome microdeletion frequency. The European Academy of Andrology and the European Molecular Genetics Quality Network guidelines indicate that the use of six STS loci (sY84, sY86, sY127, sY134, sY254, sY255) results in the detection of up to $95 \%$ of all reported Y chromosome microdeletions in the AZF regions. This study chose nine STS loci, sY84 and sY86(AZFa), sY127, sY134, and sY143(AZFb), sY152, sY254, sY255, and sY157(AZFc), to detect Y chromosome microdeletions.

Varicoceles have long been associated with male infertility as they are commonly found among infertile people and have been associated with bad seminal quality in the World Health Organization (1992). Varicoceles have an incidence of $10-15 \%$ in the general population, $30-35 \%$ in primary infertile men, and $69-81 \%$ in secondary infertile men (Gorelick and Goldstein, 1993; Sabanegh et al., 2012).

In this study, Y chromosome microdeletions were detected in $18 \%(27 / 150)$ of nonobstructive azoospermic patients with varicocele, $7.33 \%$ (11/150) in severely oligozoospermic patients, and $2.67 \%(4 / 150)$ in moderate oligozoospermic patients, but no microdeletions were detected in the mild oligozoospermic group. These results demonstrate that the spermatogenic defect is likely due to the underlying Y chromosome microdeletions, and not the varicocele itself. This is in contrast to previous studies, such as the one presented by Jarow (2001), which reported that adolescent boys with varicocele showed decreased testicular volume and/ or testicular growth. Moreover, Agarwal et al. (2007) found that sperm concentration and motility increased after varicocelectomy. Even the most recent meta-analysis demonstrated an improvement in semen parameters after treatment for varicocele (Baazeem et al., 2011).

The frequency of $\mathrm{Y}$ chromosome microdeletions was also assessed for those patients with idiopathic infertility. These microdeletions were detected in $6.00 \%(9 / 150)$ of the idiopathic non-obstructive azoospermic infertility patients, which was lower than the microdeletion frequency of the non-obstructive azoospermic patients with varicocele. Moreover, 3.33\% (5/150) of idiopathic severe oligozoospermic infertility patients possessed Y chromosome microdeletions, which was lower than the microdeletion frequency of the severely oligozoospermic patients with varicocele. Likewise, $1.33 \%(2 / 150)$ of idiopathic moderate oligozoospermic infertility patients possessed these microdeletions, which was again lower than the microdeletion frequency of the moderate oligozoospermic patients with varicocele. No microdeletions were observed in the mild oligozoospermic patients. Thus, it appears that varicocele may be associated with male infertility, but it is unlikely to be the cause of this disorder.

When comparing the $\mathrm{Y}$ chromosome microdeletion frequencies in non-obstructive azoospermic patients with varicocele determined in this study with that of previous Asian studies, several differences are evident. The $\mathrm{Y}$ chromosome microdeletion frequency of nonobstructive azoospermic patients with varicocele in our study was higher than that from other Asian Coutries, involving patients from India, Turkey, and Eastern China (Jiangsu Province) 
(Table 2). However, the data presented in this study is consistent with that found for patients in Eastern China (Shandong Province). It is interesting to note that microdeletion frequencies varied in different parts of the same country. The variation among Asian countries may be due to ethnic, regional, and STS selection differences for patient samples. The latter factor may be especially true for the study of Turkish patients where none of the patients carried Y chromosome microdeletions.

In contrast to the above comparison, $\mathrm{Y}$ chromosome microdeletion frequencies in severely oligozoospermic patients with varicocele between our study $(7.33 \%, 11 / 150)$ and previous Asian studies were very similar (Table 3). Specifically, only the microdeletion frequency from Eastern China (Shandong Province) differed significantly from those presented in this study. Interestingly, all studies of Asian severely oligozoospermic patients with varicocele had microdeletions in the AZFc regions (Table 3).

In conclusion, we recognized that our samples from Northeastern China had a higher frequency of microdeletions among non-obstructive azoospermic patients with varicocele than other Asian countries. Our results demonstrated that spermatogenic defects are due to the underlying Y chromosome microdeletions, and varicoceles are simply a phenotype in infertility patients. Although varicocele is not the true cause of male infertility, it appears to be associated with male infertility in the Northeastern Chinese population. These results emphasize the importance of genetic counseling and screening for $\mathrm{Y}$ chromosome microdeletions for infertile men with varicocele before varicocelectomy, to determine appropriate treatment plans.

\section{Conflicts of interest}

The authors declare no conflict of interest.

\section{ACKNOWLEDGMENTS}

We thank all staff of the Cytogenetic Laboratory for their excellent work. Research supported by funds from the National Population and Family Planning Commission of China (\#2011-GJKJS-07).

\section{REFERENCES}

Agarwal A, Deepinder F, Cocuzza M, Agarwal R, et al. (2007). Efficacy of varicocelectomy in improving semen parameters: new meta-analytical approach. Urology 70: 532-538.

Baazeem A, Belzile E, Ciampi A, Dohle G, et al. (2011). Varicocele and male factor infertility treatment: a new metaanalysis and review of the role of varicocele repair. Eur. Urol. 60: 796-808.

Briton-Jones C and Haines CJ (2000). Microdeletions on the long arm of the Y chromosome and their association with male-factor infertility. Hong Kong Med. J. 6: 184-189.

Dada R, Kumar R, Shamsi MB, Sidhu T, et al. (2007). Azoospermia factor deletions in varicocele cases with severe oligozoospermia. Indian J. Med. Sci. 61: 505-510.

Jarow JP (2001). Effects of varicocele on male fertility. Hum. Reprod. Update 7: 59-64.

Gao DJ, Li JS, Sun BG, Liu G, et al. (2012). Screening of Y chromosome microdeletions in infertile males with varicocele. Zhonghua Nan Ke Xue 18: 973-977.

Gatta V, Stuppia L, Calabrese G, Morizio E, et al. (2002). A new case of Yq microdeletion transmitted from a normal father to two infertile sons. J. Med. Genet. 39: E27.

Gorelick JI and Goldstein M (1993). Loss of fertility in men with varicocele. Fertil. Steril. 59: 613-616.

Krausz C, Rajpert-De Meyts E, Frydelund-Larsen L, Quintana-Murci L, et al. (2001). Double-blind Y chromosome microdeletion analysis in men with known sperm parameters and reproductive hormone profiles: microdeletions are 
specific for spermatogenic failure. J. Clin. Endocrinol. Metab. 86: 2638- 2642.

Marmar JL (2001). Varicocele and male infertility: part II. The pathophysiology of varicoceles in the light of current molecular and genetic information. Hum. Reprod. Update 7: 461-472.

Moro E, Martin P, Rossi A, Garolla A, et al. (2000). Y chromosome microdeletions in infertile men with varicocele. Mol. Cell Endocrinol. 161: 67-71.

Rao L, Babu A, Kanakavalli M, Padmalatha V, et al. (2004). Chromosomal abnormalities and Y chromosome microdeletions in infertile men with varicocele and idiopathic infertility of South Indian origin. J. Androl. 25: 147-153.

Redmon JB, Carey P and Pryor JL (2002). Varicocele--the most common cause of male factor infertility? Hum. Reprod. Update 8: 53-58.

Sabanegh E and Agarwal A (2012). Male Infertility. In: Campbell-Walsh Urology (Wein AJ, Kavoussi LR, Novick AC, Partin AW, et al., eds.). 10th edn. Saunders, Philadelphia, 636-637.

Sagnak L, Ersoy H, Ozok U, Eraslan A, et al. (2010). The significance of Y chromosome microdeletion analysis in subfertile men with clinical variocele. Arch. Med. Sci. 6: 382-387.

Simoni M, Bakker E and Krausz C (2004). EAA/EMQN best practice guidelines for molecular diagnosis of y-chromosomal microdeletions. State of the art 2004. Int. J. Androl. 27: 240-249.

Song NH, Wu HF, Zhang W, Zhuo ZM, et al. (2005). Screening for Y chromosome microdeletions in idiopathic and nonidiopathic infertile men with varicocele and cryptorchidism. Chin. Med. J. 118: 1462-1467.

Tulloch WS (1952). A consideration of sterility factors in the light of subsequent pregnancies: subfertility in the male. Edinb. Med. J. 59: 29-34.

World Health Organization (1992). The influence of varicocele on parameters of fertility in a large group of men presenting to infertility clinics. Fertil. Steril. 57: 1289-1293.

World Health Organization (1999). Laboratory manual for the examination of human semen and sperm-cervical mucus interaction. 4th edn. Cambridge University Press, Cambridge. 